\title{
Testing the Validity of Conditional Four Moment Capital Asset Pricing Model: Empirical Evidence from the Colombo Stock Exchange
}

\author{
Jayaweera M. Nishantha ${ }^{1}$
}

\begin{abstract}
The Capital Asset Pricing Model (CAPM) is one of the most used model in finance during the last five decades. This is despite heavy criticism against it along with an ongoing debate among academia about the empirical validity of the model. Three major extensions to the conventional model have been suggested; higher-moment CAPM, multi-factor model and conditional CAPM. All these models have shown mixed results in empirical studies. In the recent past, these extensions are integrated and tested for empirical validity and show some positive results (Vendrame, Tucker \& Guermat, 2016). In this study, the empirical validity of conditional four-moment CAPM is tested on the Colombo Stock Exchange (CSE) of Sri Lanka. Individual stock returns on 74 listed companies covering a 17-year period from 2000 to 2016 are used. A two step procedure is followed with the estimation of the short window time series regressions in the first step, while cross-sectional regressions are estimated in the second step. Test results show inconclusive evidence about the conditional four-moment CAPM. Risk of coskewness is significant though risk of covariance and co-kurtosis are not significant explaining the average return on individual stocks on the CSE during the period under study.
\end{abstract}

Key Words: CAPM, co-skewness, co-kurtosis, Four-moment, individual stocks JEL Classification: C1; G12

\footnotetext{
${ }^{1}$ The author is currently serving as Senior Assistant Director of the Risk Management Department. Corresponding email: nishantha@cbsl.lk. The views in this paper are expressed in the author's personal capacity and do not represent the views of the Central Bank of Sri Lanka.
} 


\section{Introduction}

The Capital Asset Pricing Model (CAPM) plays a major role in the current finance industry and in making investment decisions. The CAPM is introduced by Sharpe (1964), Lintner (1975) and Mossin (1966) following the mean-variance portfolio theory introduced by Henry Markowitz (1952). The model primarily describes the linear relationship between expected return on an asset and expected market return in excess of risk free return. Black (1972) has suggested a two-factor model to be used in the absence of the risk-free asset. Though early studies by Black, Jensen and Scholes (1972) and Fama and MacBeth (1973) support the CAPM with evidence of a linear relationship between average asset returns and market risk, Black, Jensen and Scholes (1972) fail to find empirical evidence to support the other implications of the CAPM, such as that the intercept equals the risk-free rate. Many later studies also find evidence against the CAPM. Basu (1977), Banz (1981) and Fama and French (1992) find evidence that not only beta but other factors such as earnings to price $(\mathrm{E} / \mathrm{P})$ ratio, size and book value to market value $(\mathrm{B} / \mathrm{M})$ ratio also have the explanatory power of average returns.

Despite the vast amount of empirical evidence against the CAPM, it has been widely used in finance to estimate the cost of capital for firms, to assess investment opportunities and to evaluate performance of portfolio management. Jagannathan and Wang (1996) provide three reasons for the extensive use of CAPM over the years. First, alternative asset pricing models also have failed to be proven empirically. The second is the lack of the intuitive appeal of the theories behind other models. For an example, Arbitrage Pricing Theory can only be applied to well diversified portfolios and it does not say anything about how expected returns are determined. Thirdly the uncertainty about the empirical evidence against the CAPM and their economic importance have helped the wide use of the CAPM.

However, efforts of researchers to find better models to explain the average asset returns led to some extensions to the CAPM. The first extension was introduced by Kraus and Litzenberger (1976) by introducing skewness of excess market return to the CAPM. The kurtosis was introduced to the model by Fang and Lai (1997) and empirical evidence is found in consistence with the proposed model. The studies show that investors are willing to pay a premium for assets with positive co-skewness and expect a risk premium on assets with positive kurtosis.

The evidence that the $\mathrm{P} / \mathrm{E}$ ratio, $\mathrm{B} / \mathrm{M}$, size of the firm and leverage have the power to explain the average asset returns (Basu, 1977; Banz, 1981; Fama \& French, 1992) directed towards the introduction of the second form of extension by Fama and French (1993). They introduce a three-Factor model by introducing size effect and book-to-market ratio effect in addition to the market portfolio in to the model. The third extension to the model is the conditional CAPM. Pettengil, Sundharam, and Mathur (1995) and Jagannathan and Wang (1996) suggested that CAPM is held conditionally though it is not held unconditionally. 
Empirical tests of CAPM have been subject to criticisms in various frontiers. One of the early criticism is Roll's (1977) critique on the market portfolio. He argues that the CAPM is never tested without knowing the exact definition of the market portfolio. Another criticism is on the use of ex-post returns to test the CAPM (Elton, 1999) whereas the CAPM model describes the ex-ante returns. Econometrics approaches and methodologies used to test the CAPM empirically have also been criticised and several alternatives have been proposed (Shanken, 1992; Kim, 1995). In a recent study, Ray, Savin, and Tiwari (2009) find evidence that conventional tests over-reject the CAPM and use of the new HAR based tests provide much supportive evidence for the CAPM. Vendrame, Tucker and Guermat (2016) test whether the use of individual stocks, conditional model, higher moment and other risk factors such as size effect can perform better than the traditional, static and portfolio based CAPM model and find that the use of individual stocks with higher moment, in combination with size factor and conditional model explain the cross-sectional variation in asset returns.

As in the international case, even in Sri Lanka, empirical evidence shows mixed results on the CAPM. Samarakoon (1997) concludes that there is negative relationship between beta and average return, while Thilakarathne and Jayasinghe (2014) conclude that the beta plays a significant role in explaining average returns of stocks in the CSE. Riyath and Nimal (2016) find evidence that the Fama and French (1993) three factor model performs better than the CAPM.

Many empirical studies on the CAPM assume that the asset returns are normally distributed and distributions are static. But in real world, asset returns are not normally distributed and returns vary with time (Aggarwal \& Rao, 1990; Shahi \& Shaffer, 2017). Therefore, it would be more appropriate to use a higher-moment dynamic model to explain the average return of assets.

The objective of this study is to empirically test the conditional four-moment CAPM on individual assets on the Colombo Stock Exchange (CSE), the only stock exchange in Sri Lanka. It is tested whether the co-skewness, co-kurtosis of asset returns with the market return are helpful to explain the stock returns on the CSE in addition to the market return in the conventional CAPM. The estimation of risk parameters beta, gamma and delta using one year short- windows make sure that the models are conditional. Further, instead of estimating risk parameters on portfolios, in this study parameters are estimated on individual stocks. Overall, the model integrates two extensions of the CAPM, namely the conditional CAPM and fourmoment CAPM. The analysis process closely follows Vendrame, Tucker and Guermat (2016) and Kraus and Litzenberger (1976) processes. The two steps procedure is followed; In the first stage, time series regressions are used to estimate conditional beta, gamma and delta on each stock for each year. Then these estimates are used to perform cross-sectional regressions in each year to estimate risk premiums in the second stage. 
As far as the author is aware, there is no study that has been conducted on either conditional CAPM or on the higher moment CAPM on CSE. Therefore, this would add to the literature on the Sri Lankan stock market as the first study on conditional higher-moment CAPM on the CSE, filling the existing gap. Further, this would be one of the first studies even in the international context that integrates two extensions of the CAPM, apart from the study by Vendrame, Tucker and Guermat (2016).

The study is carried out using weekly stock prices of 74 firms listed in the CSE, for the period January 2000 to December 2016. All Share Price Index (ASPI), the main index of the CSE, is used as the proxy to the market portfolio, while the three-month Treasury bill rate is used as the risk-free rate. In summary, the results provide inconclusive evidence on the conditional four-moment CAPM. Test results indicate that co-skewness can explain the average return of stocks on the CSE during the period 2000 to 2016, while the conditional covariance and cokurtosis has no explanatory power of asset returns. Moreover, the results support the evidence that the return distributions and risk parameters vary over time. Further, it shows evidence of skewness and kurtosis in return distributions.

The rest of the paper is structured as follows, in Section 2, literature on the CAPM and its extensions are discussed. The model of four-moment CAPM is outlined in Section 3. Section 4 describes data and methodology. Empirical analysis and interpretations of the test results are presented in Section 5, while Section 6 summarizes and concludes.

\section{Literature review}

Since its introduction, validity of the CAPM has been empirically tested by many researchers. While some studies (Fama \& MacBeth, 1973; Limmack \& Ward, 1990; Sauer \& Murphy, 1992) provide supportive evidence for CAPM, many studies (Black, Jensen \& Scholes, 1972; Blume \& Friend, 1973; Basu, 1977; Banz, 1981; Fama \& French; 1992) have shown evidence against the CAPM. At present, the general concession on CAPM is that the market risk is not the only factor in deciding return on an asset. However, there are ongoing debates on the validity of the CAPM, with criticism on procedures, econometrics methods and tests used to test the empirical validity of the CAPM. As a result, different methodologies, various versions and extensions to the CAPM have been introduced.

In this chapter, the next section begins with a brief discussion on the CAPM model and its assumptions. Then some of the important empirical evidence available in favour and against the CAPM is presented. There are criticisms against the CAPM and empirical tests conducted on the CAPM. Those criticisms are discussed before discussing the literature on the extensions to the CAPM. The CAPM is tested using empirical data from the Colombo Stock Exchange (CSE). Therefore, finally a brief introduction to the CSE and some studies carried out in relation to the CAPM model in the CSE are discussed. 


\subsection{Introduction to the Capital Asset Pricing Model (CAPM)}

Following the mean-variance portfolio theory of Markowitz (1952), Sharpe (1964) and Lintner (1975) proposed a model to explain the average return on individual assets. As in many economics and financial models, the CAPM is derived under certain assumptions. Since the CAPM is derived based on the Markowitz mean-variance portfolio theory, the CAPM requires the same assumptions to be held and two more assumptions about investors ability to lend and borrow money and their homogenies expectations. The key assumptions of the CAPM are as follows:

i) Investors view the outcome of any investment as being represented by a probability distribution of returns.

ii) Investors maximize one period expected utility. This requires either the returns to be normally distributed or investors have quadratic utility functions.

iii) Investors make their investment decisions based on expected returns and standard deviations of returns.

iv) Investors are risk averse. They prefer higher expected return to lower expected return for a given level of risk as measured by standard deviation or lower risk to a higher risk for a given level of expected return.

v) There are no transaction costs or taxes involved in investing in assets.

vi) Investors can borrow and/or lend any amount of money at the risk-free rate of interest.

vii) All investors have the same view on the return distributions on all the investments, i.e., have homogeneous views about investments.

(Sharpe, 1964; Lintner, 1975; Mossin,1966)

Based on the above assumptions, the model relates the expected return on an asset to the riskfree rate, market return in excess of the risk-free rate and the assets' responsiveness to the market excess return in a linear fashion.

Mathematically the CAPM model can be represented by equation (1).

$$
E\left(R_{i}\right)=r_{f}+\beta_{i}\left[E\left(R_{m}\right)-R_{f}\right]
$$

Where $\mathrm{E}($.$) is the expected operator, R_{i}$ - return on the ith stock, $R_{m}$ - return on the market, $R_{f}$ - risk free rate, and $\beta_{i}=\frac{\operatorname{Cov}\left(R_{i}, R_{m}\right)}{\sigma^{2}\left(R_{m}\right)}$ - measure of the systematic risk of stock i.

$$
\begin{aligned}
& \sigma^{2}\left(R_{i}\right)=E\left[R_{i}-E\left(R_{i}\right)\right]^{2} \\
& \operatorname{Cov}\left(R_{i}, R_{m}\right)=E\left\{\left[R_{i}-E\left(R_{i}\right)\right]\left[R_{m}-E\left(R_{m}\right)\right]\right\}
\end{aligned}
$$


Here the market portfolio is a value weighted portfolio of all risky assets available to an investor. There are three main implication of the model (Fama \& MacBeth, 1973).

a) The model implies that there exists a linear relationship between expected excess return on any asset and its beta.

b) The covariance between the asset return and the market return is the only variable that explains the variation in returns between assets. Accordingly, investors are awarded for holding the systematic risk and not rewarded for bearing the idiosyncratic risk.

c) The expected excess return of an asset is proportional to its beta. That is, higher the risk (beta) of an asset higher the expected return on that asset and the market risk premium is positive.

However, it is worth to note that the model is a single period static model. Further, it does not clarify about what the single period is, whether it is a month, quarter, year or several years. In reality, the economies are dynamic and therefore the (expected) return on assets also changes with time. The model expects beta to be static, at least during the single period. Moreover, the market portfolio plays a key role in the model, but there is no proper definition to the market portfolio. Asset returns are expected to be normally distributed, but observed otherwise. All these pitfalls have created enough ambiguities on the empirical evidence about the CAPM as discussed in the following subsections.

\subsection{Evidence in favour of the CAPM}

As one of the major breakthroughs in Asset Pricing Theory, the CAPM attracted the attention of many academia and finance managers. Sharpe (1964) and Lintner (1975) developed the CAPM model theoretically without any empirical evidence to support the model. In a different approach, Mossin (1966) also developed the same model and introduced the concept of market risk premium. Following those developments, many studies have been carried out to assess the empirical validity of the CAPM.

In one of the early studies using monthly returns of common stocks traded on the NYSE for the period January 1926 to June 1968, Fama and MacBeth (1973) found supportive evidence for the CAPM. In their study, they used a three-step approach and this method was widely used in subsequent studies. They conclude that, on average, there is a positive linear relationship between beta and return, despite the fact that they observe nonlinearity in sub periods. Therefore, this has been interpreted as a weak support for the CAPM by Schwert (1983). Further Fama and MacBeth (1973) conclude that no other measure of risk systematically affects the average return. In Fama and MacBeth (1973) study, as in many other studies, the average realised return is used as a proxy for expected return and realised returns of an equity index is used as a proxy for market return. Apart from this affirmative evidence 
from the US, Sauer and Murphy (1992), and Limmack and Ward (1990) found positive evidence from Germany and the UK, respectively.

\subsection{Evidence against the CAPM}

As discussed in Section 2.1 (Introduction to the CAPM), there are three main implications of the model. The model can be empirically validated only if empirical evidence supports these three implications. Almost every test of CAPM is based on either a time series regression or a cross sectional regression. In the cross-sectional regression approach, average asset returns are regressed on estimated betas while in the time series regression approach, excess return on an asset is regressed on market excess return. In the cross-sectional regression approach, it is expected that the intercept term to be equal to the risk-free rate and coefficient on beta to be equal to the average market excess return over the risk-free rate. In the time series approach, the intercept, which is called Jensen alpha, is expected to be zero. Most of the studies based on cross-sectional regressions find a linear relationship between beta and returns but their slopes are too small. Further, the estimated intercept significantly different from the risk-free rate. The same is evident in the time series regressions, as assets with high beta recorded negative intercepts and assets with low beta recorded positive intercepts (Black, Jensen \& Scholes, 1972; Blume \& Friend, 1973; Fama \& French; 1992, 2004).

The CAPM also implies the completeness of beta, i.e., the market risk is the only factor that explains the differences in excess returns across assets. Many studies have challenged the role of beta as a complete and efficient measure of systematic risk of an individual asset as they find other factors, such as earnings-price ratio (Basu, 1977), size of the firm in terms of market capitalization (Banz, 1981), leverage (Bhandari, 1988), and book to market value (Rosenberg, Reid and Lan 1985) affect the asset returns. The most significant evidence against the CAPM is provided by Fama and French (1992) following the same methodology by Fama and MacBeth (1973) but for data of non-financial firms on the NYSE, AMEX and NASDAQ from 1963 to 1990. Fama and French claimed that the relationship between beta and asset returns disappears in that period. Moreover, they show that size effect and book to market value is able to explain the average stock return. Consequently, they introduced a three-factor model for asset pricing.

\subsection{Criticisms on CAPM and empirical tests}

However, none of these studies are exempt from criticism. These criticisms can be broadly categorised into two frontiers; criticisms based on the validity of the assumptions of the CAPM and criticisms based on the shortfalls in the econometrics approaches. Roll's (1977) critique on the market portfolio is one of the famous critiques on the assumptions of the CAPM. In the CAPM the market portfolio plays a major role. However, it is not clear what assets are included in the market portfolio. Therefore, Roll (1977) argue that the CAPM can never be tested without knowing the exact composition of the true market portfolio. 
Almost all the studies discussed so far use the ex-post observed returns, but the CAPM model specifies the relationship between expected return and risk. The problem of ex-ante returns being proxied by ex-post returns is criticised by Elton (1999) providing evidence of realized negative excess returns in the stock market for the 11-year period from 1973 to 1984. This problem has been addressed in several studies, which have been concluded in favour of the CAPM. Claus and Thomas (2001) use equity analysts forecast and current market price to find that the equity premium is approximately three percent. Fama and French (2002) estimate the equity premium using fundamental based returns and conclude that the average realised equity premium is much higher than the expected equity premium during the period 1951 to 2000.

Another important assumption in Markowitz portfolio theory, on which the CAPM has been developed, is that the asset returns are normally distributed. But there is empirical evidence that returns are not normal (Aggarwal \& Rao, 1990; Barnea \& Downes, 1973; Fama, 1965; Officer, 1972). This observation has led to the introduction of higher moment CAPM. Further, Shahi and Shaffer (2017) conclude that the distribution of asset returns changes with time, therefore challenging the validity of the CAPM. Some recurrent changes to the return distribution has been observed by Ariel (1987) and Penman (1987).

Errors in variables (EIV) is one of the criticisms associated with the econometrics approaches used in the empirical test of the CAPM. EIV occurs due to the two pass procedure followed in estimation. The result is the underestimation of the market risk premium and overestimation of the other risk premiums (Shanken, 1992; Kim, 1995). Alternative methods of estimations to overcome the EIV problem have been proposed by Gibbons (1982), Shanken (1992), Kim (1995) and Malloch, Philip and Satchell (2016).

Appropriateness of different estimation procedures such as OLS, WLS, GLS, and GMM to empirically test the CAPM is also discussed in the literature. In each method, there are merits and demerits and there is no consensus about the best procedure to follow. Shanken and Zhou (2007) provide a good comparison between different estimation methods based on a simulation analysis.

In addition to the empirical challenges to the validity of the CAPM there are some theoretical challenges to the CAPM. The first challenge is imminent from the behavioural economists who challenge the expected utility theory (EUT) on which mean-variance portfolio theory is derived. Behavioural economists based on Prospect Theory by Kahneman and Tversky (1979) argue that the investors are not rational and efficient all the time as assumed in the EUT. In a very recent paper using an algebraic analysis Lai and Stohs (2015) show that the CAPM is having an endogeneity problem or circularity. They show that the beta of an asset depends on its excess return and therefore proportional to the same. As a result, contrary to the CAPM, the excess return of the asset determines beta, instead beta determines the excess return. Thus, it is incorrect to interpret as beta represents the systematic risk. 
In the attempts to address the above criticisms several extensions and different forms of CAPM models haves been suggested. These extensions are briefly discussed in the following sub section.

\subsection{Extensions to the CAPM}

The vast amount of empirical evidence against the CAPM directed to extensions of the CAPM. The first extension of the CAPM is introduced by Kraus and Litzenberger (1976) by incorporating the effect of skewness. Derivation of three moment CAPM model assumes that the investors' expected utility can be represented by the first three moments; the mean, variance and skewness, of the end of period wealth and investors maximize the expected utility. Further it assumes that investors are averse to variance as in the CAPM but prefer to positive skewness. Investors are willing to pay a premium for assets with positive skewness as they receive the premium for the risk. Authors also derive a quadratic market model that corresponds to the three moment CAPM. They went on to test their model empirically using the stock data on the NYSE from 1926 to 1970. The portfolio formation method similar to Black, Jensen and Scholes' method (1972). Fama and MacBeth's (1973) procedure is used to address the problem of estimation errors. But they use realised deflated excess rate of return. Finally, Kraus and Litzenberger (1976) conclude that there is a significant price for systematic skewness and a zero intercept as predicted by the model. Friend and Westerfield (1980) conducted a similar study that incorporates both stocks and bonds in to the analysis and found contradicting results to Kraus and Litzenberger (1976).

The model further extended to incorporate the fourth moment of asset returns by kurtosis by Fang and Lai (1997). In this model, it is assumed that investors are averse to kurtosis. Thus, the expected return for kurtosis is positive. The model was tested empirically following the grouping method suggested by Kraus and Litzenberger (1976) and using stock data on NYSE stock for the period 1969 to 1988. Empirical evidence supports the model. Further, Hung (2008) shows that the higher moment CAPM model is unable to produce superior results than the traditional CAPM model in one period ahead forecasting.

The inclusion of skewness and kurtosis can be justified by the Prospect Theory (Kahneman \& Tversky, 1979). In Prospect Theory, it is assumed that the investors assigned higher weights to losses than to gains. On the other hand, since late 1980s the global financial markets have experienced major crises. Therefore, most likely higher moment models will be able to capture the systematic risk in the current asset markets (Vendrame, Tucker \& Guermat, 2016).

While the higher moment CAPM model tries to fill the gap of the inability of single factor beta to explain the asset returns by adding higher moments of the return distribution, Fama and French (1993) introduce a three-factor model by adding the size of the firm (SMB) and leverage (HML) factors into the model and conclude that the market factor together with SMB and HML explain the average stock returns. Series of latter studies confirm the three-factor model (Fama \& French, 1996a, 1996b, 1998, 2002). 
The other major branch of extension to the traditional CAPM is the conditional CAPM. Pettengil, Sundharam and Mathur (1995) suggest the use of a conditional beta approach when realized market returns are used to test the CAPM. Pettengil, Sundharam and Mathur (1995) argue that when the market excess return is positive the relationship between beta and realized return is also positive. But when the market excess return is negative then the relationship between beta and realized return is negative. They carry out an empirical test using stocks that are included in the CRSP equally-weighted index for the period 1926 to 1990. Their evidence supports the existence of a systematic relationship between beta and returns for the whole sample periods as well as for subsample periods and positive trade-off between market risk and return. Similar results were found in the Swiss stock market by Isovak (1999) for the period 1983-1991 and by Tang and Shum (2003) in 13 international stock markets.

In line with the argument that the market risk premium varies with time and therefore the beta, Jaganthan and Wang (1996) suggest a different form of the conditional CAPM. Jaganathan and Wang (1996) contend that the CAPM is derived based on the assumptions that the investors live only one period, which is far away from reality. During a business cycle, the relative risk of firms varies, therefore the expected returns and beta vary with time and depend on the status of the economy. Therefore, they suggest a conditional version of the CAPM and interpret it as "the expected return on an asset based on the information available at any given point of time is linear in its conditional beta" (Jaganathan \& Wang, 1996). They test the model empirically using the CRSP value weighted index as the proxy for the market portfolio and observed that the 30 percent of the return variation is explained by the conditional CAPM. Further, once they include a measure of return on human capital to the market portfolio the model can explain 50 percent of the variation.

However, Freeman and Guermat (2006) criticise the econometric tests used in existing empirical studies on conditional CAPM and proposed an adjusted test. Lewellen and Nagel (2006), also argue that the conditional CAPM has failed to explain the pricing anomalies such as size effect and loser-winner effect. Meantime they have suggested a direct method of estimating the conditional CAPM model using short window regression and therefore avoiding the use of conditioning information.

Vendrame, Tucker and Guermat (2016) carried out a study to investigate the drawbacks that may have contributed to the weak and conflicting outcomes of the empirical studies. Their study tests whether the use of individual stocks, conditional model, higher moment and other risk factors such as size effect can perform better than the traditional, static and portfolio based CAPM model. In summary, the results indicate that the use of individual stocks with higher moment in combination with size factor and conditional model explain the crosssectional variation in asset returns. 


\subsection{Colombo Stock Exchange}

The Colombo Stock Exchange (CSE) is the only stock exchange in Sri Lanka and was established in 1985. Market capitalization as at 14th June, 2017 is Rs 3,068.3 bn (USD 20 bn) with the 295 listed companies representing 20 business sectors. There are two market indices; All Share Price Index (ASPI) and S\&P 20 SL index. In the recent past, attention of foreign investors on the CSE has increased as an emerging market in the South Asian Region.

Only a limited number of studies have been carried out on the CSE. Among them early studies done by Samarakoon (1997) contributed significantly. Samarakoon (1997) documented that the relationship between average return and beta is negative while there is a strong positive relationship between earning-price ratio and average return. In an attempt to identify a better model to explain cross sectional variation in stock returns in the CSE, Riyath and Nimal (2016) find evidence that Fama and French (1993) three factor model perform better than the CAPM. Both these studies closely follow the Fama and MacBeth (1973) procedure.

In contrast to the above observations, Thilakarathne and Jayasinghe (2014) conclude that the beta plays a significant role in explaining average returns of stocks in the CSE and size of the company has a weak positive relationship. Further, they find that earning-to-price ratio has a weak negative relationship with average return. As in the international case, mixed results for the validity of CAPM is observed in the CSE.

However, all these studies on the CSE test the validity of the original form of the CAPM or multifactor models. According to the best of my knowledge, there is no study that has tested the validity of higher order moment CAPM on the CSE. Further, many studies on higher moment CAPM have been carried out on well-developed markets such as US and there is not that much studies carried on emerging markets such as Sri Lanka. In this study, it is attempted to fill that gap by testing the four-moment CAPM on CSE in Sri Lanka.

\section{The model: four-moment CAPM}

The original form of the CAPM as specified by equation (1) states that the expected return of an asset is determined by the beta factor of the particular asset and the relationship between beta, and expected return is linear. However, as many later time relevant studies found empirical evidence against this form of CAPM (Black, Jensen \& Scholes, 1972; Fama \& French, 1992) some extensions to the CAPM are introduced, as discussed in Section 2.5. In this study, the validity of the four-moment CAPM is tested in the CSE. Therefore, a brief introduction to the four-moment CAPM model and related concepts such as co-skewness and co-kurtosis are provided in this section.

In addition to the expected return and variance of return in the traditional CAPM, the third and fourth moment of the return distribution are considered in the four-moment CAPM. 
Skewness (S3) and kurtosis (K4) are defined as follows.

$$
\begin{aligned}
& \text { Skewness }=S^{3}\left(R_{i}\right)=E\left[R_{i}-E\left(R_{i}\right)\right]^{3} \\
& \text { Kurtosis }=k^{4}\left(R_{i}\right)=E\left[R_{i}-E\left(R_{i}\right)\right]^{4}
\end{aligned}
$$

And co-skewness and co-kurtosis between asset $\mathrm{i}$ and market portfolio are defined as:

$$
\begin{aligned}
& \text { Co-skewness }=\operatorname{Cos}\left(R_{i}, R_{m}\right)=E\left\{\left[R_{i}-E\left(R_{i}\right)\right]\left[R_{m}-E\left(R_{m}\right)\right]^{2}\right\} \\
& \text { Co-kurtosis }=\operatorname{Cok}\left(R_{i}, R_{m}\right)=E\left\{\left[R_{i}-E\left(R_{i}\right)\right]\left[R_{m}-E\left(R_{m}\right)\right]^{3}\right\}
\end{aligned}
$$

Following Fang and Lai (1997) and under the mean-variance-skewness-kurtosis optimization the four moment CAPM model can be written as

$$
\begin{gathered}
E\left(R_{i}\right)-R_{f}=\lambda_{\beta} \frac{E\left[\left(R_{i}-\bar{R}_{i}\right)\left(R_{m}-\bar{R}_{m}\right)\right]}{\left[E\left(R_{m}-\bar{R}_{m}\right)\right]^{2}}+\lambda_{s} \frac{E\left[\left(R_{i}-\bar{R}_{i}\right)\left(R_{m}-\bar{R}_{m}\right)^{2}\right]}{\left[E\left(R_{m}-\bar{R}_{m}\right)\right]^{3}}+ \\
\lambda_{k} \frac{E\left[\left(R_{i}-\bar{R}_{i}\right)\left(R_{m}-\bar{R}_{m}\right)^{3}\right]}{\left[E\left(R_{m}-\bar{R}_{m}\right)\right]^{4}} \\
E\left(R_{i}\right)-R_{f}=\lambda_{\beta} \beta_{i}+\lambda_{s} \gamma_{i}+\lambda_{k} \delta_{i} \\
\beta_{i}=\frac{E\left[\left(R_{i}-\bar{R}_{i}\right)\left(R_{m}-\bar{R}_{m}\right)\right]}{\left[E\left(R_{m}-\bar{R}_{m}\right)\right]^{2}}, \gamma_{i}=\frac{E\left[\left(R_{i}-\bar{R}_{i}\right)\left(R_{m}-\bar{R}_{m}\right)^{2}\right]}{\left[E\left(R_{m}-\bar{R}_{m}\right)\right]^{3}} \text { and } \delta_{i}=\frac{E\left[\left(R_{i}-\bar{R}_{i}\right)\left(R_{m}-\bar{R}_{m}\right)^{3}\right]}{\left[E\left(R_{m}-\bar{R}_{m}\right)\right]^{4}}
\end{gathered}
$$

Equation (8) and (9) state that the expected excess return of any individual stock is a linear function of three co-moments of the stock return with the market portfolio.

$\lambda_{\beta}$-risk premium for the market risk (ie: market risk premium)

$\lambda_{\gamma}-$ risk premium for risk of standardized co-skewness

$\lambda_{\delta}-$ risk premium for risk of standardized co-kurtosis

It is assumed that the asset with positive co-skewness $\left(\left[R_{i}-E\left(R_{i}\right)\right]>0\right)$ tends to deliver higher return than the expected return and therefore is considered as a less risky asset. As a consequence, investors are willing to pay a premium for holding an asset with positive coskewness (Kraus \& Litzenberger, 1976; Friend \& Westerfiels, 1980; Vendrame, Tucker \& Guermat, 2016). Meanwhile, the asset with positive co-kurtosis tends to deliver large losses and therefore is considered as a risky asset. Like in the case of co-variance in the presence of positive co-kurtosis investors need to compensate for holding the risk and expect higher expected return (Fang \& Lai, 1997; Vendrame, Tucker \& Guermat, 2016). Therefore, in the four-moment CAPM a negative value for $\lambda_{\gamma}$ and positive values for $\lambda_{\beta}$ and $\lambda_{\delta}$ are expected. 


\section{Data and methodology}

\subsection{Data}

Weekly data of stock prices of 74 firms out of 295 firms listed in the CSE is obtained from the data library of the CSE for the period of January 2000 to December 2016. Most of the stocks do not trade frequently in the CSE and therefore the mostly traded 74 firms during the sample period are selected for the study. As the market portfolio is proxied by the ASPI, weekly data for the same is obtained from the data library of the CSE for the same period. The three-month Treasury bill rate is used as the risk-free asset and weekly data on a 3-month Treasury bill rate are obtained through Bloomberg.

As the market price of stocks are available, return on individual stock and market are calculated as $R_{i t}=\ln \left(\frac{P_{t}}{P_{t-1}}\right)$ where $\mathrm{P}_{\mathrm{t}}$ represents the price of the stock/ASPI at time t. As the interest rate of the 3-month Treasury bill rate is expressed in annualised terms it is adjusted to a weekly rate of return by dividing 52 . Then weekly excess return is calculated for each and every stock in the sample and for the market portfolio proxied by the ASPI.

Preliminary analysis of excess returns show that there is positive correlation between stock excess returns and market excess return (Table 1, Appendix A). The correlation coefficients are calculated for the whole sample period and all 74 coefficients are significant. Table 2 (Appendix A) shows the summary statistics for excess stock returns and market excess return for the whole sample period. Test for normality is performed using the Jarque-Bera test and the resulting test statistics are also reported in Table 2. Distributions of returns for all stocks and market significantly deviate from normal distribution as all test statistics are significant. This observation justifies the use of four-moment CAPM to explain the average stock returns.

\subsection{Methodology}

The aim of the study is to test the validity of the four-moment CAPM represented by equation (9) in Section 3. In the absence of skewness and kurtosis, this model is equivalent to the traditional CAPM model. As explained in Section 3, investors expect high return for the assets with high co-variance and co-kurtosis with the market and are willing to pay a premium for assets with positive co-skewness with the market. Accordingly, testing the validity of fourmoment CAPM is equivalent to testing the following hypothesis:

$$
\begin{aligned}
& H_{01}: \lambda_{\beta}>0 \\
& H_{02}: \lambda_{s}<0 \\
& H_{03}: \lambda_{k}>0 \\
& \text { in the equation (9). }
\end{aligned}
$$


In many empirical studies following Fama and MacBeth (1973) and Black, Jensen and Scholes, (1972) the CAPM is tested on portfolios instead of individual assets. There are criticisms on use of portfolios to test the CAPM. It is argued that grouping reduces the variation in betas and lowers the power of statistical tests (Kim,1995). Further, Kim (1995) argues that important information on risk premium is lost when grouping is used. Therefore, in this study individual stocks are used as in Vendrame, Tucker and Guermat's (2016) study.

Further, many empirical studies have been criticised for the use of the static model that assumes that the return distribution does not change over time (Ariel, 1987; Penman,1987; Shahi \& Shaffer, 2017). The solution for that problem is to use the conditional CAPM. Again, following Vendrame, Tucker and Guermat (2016) the direct estimation method proposed by Lewellen and Nagel (2006) is used to overcome the limitation of the static model. Therefore, the following two steps estimation procedure is followed.

In step one $\beta, \gamma$ and $\delta$ for each and every stock for each one year period are estimated as in Kraus, and Litzenberger's, (1976) and Vendrame, Tucker and Guermat's (2016) studies by estimating the following three regressions.

$$
\begin{aligned}
& r_{i t}=\alpha_{1}+\beta_{i} r_{m t}+\mu_{t} \\
& r_{i t}=\alpha_{2}+\gamma_{i} r_{m t}^{2}+v_{t} \\
& r_{i t}=\alpha_{3}+\delta_{i} r_{m t}^{3}+\varepsilon_{t}
\end{aligned}
$$

where, $r_{i}=\frac{R_{i}-R_{f}}{R_{f}}$ and $\bar{r}_{i}=\frac{\overline{R_{l}-R_{f}}}{\bar{R}_{f}}$ are the deflate excess returns introduced by Kraus, and Litzenberger (1976). The regression models (10) - (12) are estimated using the OLS method for each year and for each security, and thus obtaining 1,258 estimates for each of the three conditional co-moments beta, gamma and delta.

The cross-sectional regression of average excess returns, i.e., $\bar{r}_{i t}$, on one period lagged conditional co-moments (beta, gamma and delta) is performed in the second step to estimate the risk premia for each year.

$$
\bar{r}_{i t}=\alpha_{t}+\lambda_{\beta t} \beta_{i(t-1)}+\lambda_{\gamma t} \gamma_{i(t-1)}+\lambda_{\delta t} \delta_{i(t-1)}+u_{i}
$$

Then following Fama and MacBeth's (1973) method, as Vendrame, Tucker and Guermat (2016) did, annual risk premiums are averaged and tested for significance using the t-test. Total market risk premium is estimated as the sum of individual risk premiums.ie: 
total market risk premium $=\lambda_{\beta t}+\lambda_{\gamma t}+\lambda_{\delta t}$ and the significance is tested using the $\mathrm{t}$ test. The use of one year rolling window to obtained estimates of $\beta, \gamma$ and $\delta$ ensures that we estimate the conditional models.

The econometrics software "E-views" is used to carry out the required data manipulations and estimations. Weekly stock prices, index value of ASPI and three-month Treasury bill rates are uploaded to E-views. Then two E-views programs are used in the process of estimation and hypothesis testing where each corresponds to the two stages of the methodology. Adjustment of T-bill rates, calculation of weekly deflated excess returns for each firm and for the market, generation of data series for square and cube of excess market return and finally estimation of time series regressions for each firm in each year are performed in the first program. All together 3,774 estimates of beta, gamma and delta are obtained in the first stage. The second program performs 16 cross-sectional regressions of mean excess return on one year lagged estimated betas, gammas and deltas for each year to estimate the risk premiums that correspond to each of the three risk factors for each year. In total 48 risk premiums are estimated in the second stage. Then total market risk premium is calculated as the sum of risk premium for beta, gamma and delta. Finally, to test the significance of average risk premiums conventional one sample t-test is used in each of the four series separately. The outcomes of these analyses are discussed in the next section.

\section{Empirical Analysis}

The aim of this study is to test the validity of the four-moment CAPM in the Sri Lankan stock market using data on the CSE. As explained in the previous section, the two-step procedure is carried out to empirically test the hypotheses mentioned in previous section. Weekly stock prices of 74 firms traded in the CSE during year 2000 to 2016 are used in the analysis. Table 2 (Appendix A) shows the skewness and kurtosis of excess return for the whole sample period for each and every firm. These results provide some evidence of non-normality of return distributions in line with Aggarwal and Rao (1990), Barnea and Downes (1973), Officer (1972), and Shahi and Shaffer (2017).

At the first stage of the analysis, time series regressions given by equations (10) to (12) are estimated for each firm and for each year to estimate beta, gamma and delta. The results of these estimates are summarised in Table 3 to 6 (Appendix A). Maximum and minimum values of the estimates of beta, gamma and delta for each year are provided in Table 3 (Appendix A), while Table 4 (Appendix A) summarises the beta estimates for individual firms. Table 5 and 6 (Appendix A) summarise the gamma and delta estimates for individual firms respectively. These results provide evidence that the risk measures beta, gamma and delta are time varying. For an example, maximum beta for firm 1 is 2.2597 and the minimum is 0.5009 during this 17 
years' period. The estimates for gamma for the same firm shows much more variation recording a high of 25.75 and a minimum of -30.84. Same kind of variation in other risk parameters can be observed in the results. This observation of time varying risk measures is consistent with Ang and Chen (2007) and justifies the use of conditional CAPM rather than conventional static CAPM in testing the validity of CAPM, as proposed by Jaganthan and Wang (1996).

Having estimated beta, gamma and delta for each firm for each year in the first stage, crosssectional regressions of deflated mean excess returns of firms on one year period lagged beta, gamma and delta are performed in the second stage (Equation 13). Risk premiums for beta, gamma and delta are estimated for each year through the estimation of these cross-sectional regressions and results are provided in Table 7 (Appendix A). None of the coefficients are significant at 10 per cent significant level for years 2001, 2003, 2011, 2013 2015, and 2016. Although insignificant intercept supports the CAPM, insignificant risk premiums do not support the four-moment CAPM. In year 2002 the intercept is not significant while all other three risk premiums are significant at a 10 per cent level. However, in that year sign of the market risk premium (ie beta premium) is negative and is against expectation. Last two columns of Table 7 (Appendix A) shows adjusted R2 value of the regression and the probability of F-statistics as measures of goodness of fit. Maximum R2 value of 0.0835 is recorded in year 2011. All regressions have very low R2 values, indicating that low explanatory power of risk factors studied. Further, only the models for years 2002, 2007 and 2012 are significant at 5 per cent significant level. Overall, these individual regressions provide less supportive evidence for CAPM.

The test of the conditional four-moment CAPM is carried out on average premiums and results are shown in Table 8 (Appendix A). As expected by theory, intercept term is insignificant. Further sign of risk premium for skewness and kurtosis are negative and positive, respectively. These observations are consistent with the theoretical expectation of the model. However, all these are insignificant at 5 per cent level, yet the risk premium for skewness is significantly different from zero at 10 per cent significant level. Therefore, it can be concluded that co-skewness is significant at the 10 per cent significant level in explaining average stock returns on the CSE during 2000 and 2016.

The sign of market risk premium is negative and insignificant at 10 per cent level. More interestingly total market risk premium is also negative and insignificant even at the 10 per cent significant level. Overall, test results provide inconclusive evidence on the conditional four moment CAPM.

These findings agree up to some extent with the results of Kraus and Litzenberger (1976) and Vendrame, Tucker and Guermat (2016) where they conclude that there is a price for positive co-skewness. Moreover, the insignificant risk premium on co-kurtosis is also consistent with 
the observations of Vendrame, Tucker and Guermat (2016). The result of negative beta is consistent with Samarakoon (1997) as he finds average return has a negative relationship with beta on the CSE.

However, findings of this study contradict with the results of Vendrame, Tucker and Guermat (2016) in many ways. First, using conventional t-statistics Vendrame, Tucker and Guermat (2016) find that the intercept term is different from zero, where as in my study intercept is insignificant. Further their results show that the market risk premium, and the total market premium are significant. Fang and Lai (1997) also find that empirical evidence supports the four-moment CAPM and contradicts with the results of this study.

Finally, it must be noted that there are limitations to this study. The most influential one would be the nonsynchronous trading problem due to the low trading frequency of many stocks in the CSE market, though some measures have been taken to minimize this problem. Secondly, the use of OLS and conventional t-statistics with non-normal returns may not be appropriate. In order to overcome this problem, and possible autocorrelation and heteroscedasticity problem method of GMM could be used in the estimation process and Newey-West HAC standard errors could be used (Newey \& West, 1987; 1994) in hypothesis testing. Future studies use the GMM method to overcome this problem. Further, data of a longer time period with different frequency of return calculation (daily, weekly and monthly) may be used in future studies. In this study the model integrates only two extensions of the CAPM model. Thus, the scope of a future study can be extended to integrate all three extension of the CAPM and test the four-moment CAPM with augmented Fama-French factors.

\section{Summary and Conclusions}

Introduction of the CAPM is considered as one of the major breakthroughs in finance. Since its introduction by Sharpe (1964), Lintner (1975) and Mossin (1966), the model is heavily used by finance managers of firms as well as in the academic world. The simplicity of the model and intuitive appeal of the model attracted the practitioners in the finance industry. The absence of any other alternative model with good empirical support also helps the model to be popular among practitioners (Fama \& French, 2004). Moreover, it attracted the attention of academics not only for that reason but also the criticisms levelled against it. Initially, researchers tried to empirically validate the model (Black, Jensen \& Scholes, 1972; Fama \& MacBeth, 1973, Blume \& Friend, 1973). With more evidence against the CAPM, researchers sought for variations of the CAPM and as a consequence three extensions are introduced. Introduction of skewness by Kraus and Litzenberger (1976) and latter higher order moments (Fang \& Lai, 1997) is the first extension to the CAPM. Then the three-factor model is suggested by Fama and French (1993) and conditional CAPM (Pettengil, Sundharam, \& 
Mathur, 1995; Jaganthan \& Wang, 1996). In a very recent study, Vendrame, Tucker and Guermat (2016) integrates these three extensions and test on the NYSE.

In this study, the validity of conditional four-moment CAPM is empirically tested on individual stocks listed on the CSE. The study closely follows Vendrame, Tucker and Guermat's (2016) study. Weekly data of 74 firms on the CSE for the period of 2000 to 2016 were used. The analysis was carried out in two steps; in the first step, short-window time series regressions were performed to estimate beta, gamma and delta and these estimates are used in the second step cross-sectional regressions to estimate the risk premiums. Conventional t-test was carried out to test the significance of average risk premium.

The preliminary analysis of return data shows evidence of skewness and kurtosis of return distribution. Further, average beta, gamma and delta estimate for each 17 year indicates the time varying nature of risk parameters.

The overall results of the test provide inconclusive evidence on the conditional four-moment CAPM. Risk premium for co-skewness is significant at a 10 per cent significant level, while covariance and co-kurtosis risks are not significant in explaining individual stock returns in the CSE during 2000 to 2016. Moreover, the average intercept term over the full sample period and in 8 of the cross-sectional regressions are not significantly different from zero. This observation supports the conditional four-moment CAPM. The positive and negative signs of risk premiums for gamma and delta, respectively, are observed as expected by the underlying assumption of the model.

Nevertheless, total market risk premium calculated as the sum of individual risk premium is also not significantly different from zero, and caries a negative sign. More interestingly, the sign of the market risk premium is negative, indicating the possibility of a negative relationship between beta and average returns, though it is not significant. Overall, this study provides inconclusive evidence on the four-moment CAPM on the CSE.

The low frequency of trading in many stocks on the CSE may have led to this result. According the Econometric view, there is a possibility of improvement of this study by using the GMM in the estimation process and HAC standard deviations in hypothesis testing. As there is some empirical evidence that the three-factor model can explain the stock returns on CSE one can extend the study by including those factors to this model and testing the fourmoment CAPM with Fama-French factors. 


\section{References}

Aggarwal, Raj, and Ramesh P. Rao. "Institutional ownership and distribution of equity returns." Financial Review 25.2 (1990): 211-229.

Ang, Andrew, and Joseph Chen. "CAPM over the long run: 1926-2001." Journal of Empirical Finance 14.1 (2007): 1-40.

Ariel, Robert A. "A monthly effect in stock returns." Journal of Financial Economics 18.1 (1987): 161-174.

Banz, Rolf W. "The relationship between return and market value of common stocks." Journal of Financial Economics 9.1 (1981): 3-18.

Barnea, Amir, and David H. Downes. "A reexamination of the empirical distribution of stock price changes." Journal of the American Statistical Association 68.342 (1973): 348350 .

Basu, Sanjoy. "Investment performance of common stocks in relation to their price-earnings ratios: A test of the efficient market hypothesis." The Journal of Finance 32.3 (1977): 663-682.

Bhandari, Laxmi Chand. "Debt/equity ratio and expected common stock returns: Empirical evidence." The Journal of Finance 43.2 (1988): 507-528.

Black, Fischer. "Capital market equilibrium with restricted borrowing." The Journal of Business 45.3 (1972): 444-455.

Black, Fischer, Jensen, Michael C., and Myron S. Scholes. "The capital asset pricing model: Some empirical tests." Studies in the Theory of Capital Markets (1972).

Blume, Marshall E., and Irwin Friend. "A new look at the capital asset pricing model." The Journal of Finance 28.1 (1973): 19-34.

Claus, James, and Jacob Thomas. "Equity premia as low as three percent? Evidence from analysts' earnings forecasts for domestic and international stock markets." The Journal of Finance 56.5 (2001): 1629-1666.

Elton, Edwin J., "Expected return, realized return and asset pricing tests." The Journal of Finance 54.4 (1999): 1199-1220.

Fama, Eugene F. "The behavior of stock-market prices." The Journal of Business 38.1 (1965): 34-105.

Fama, Eugene F., and Kenneth R. French. "The cross-section of expected stock returns." The Journal of Finance 47.2 (1992): 427-465.

Fama, Eugene F., and Kenneth R. French. "Common risk factors in the returns on stocks and bonds." Journal of Financial Economics 33.1 (1993): 3-56.

Fama, Eugene F., and Kenneth R. French. "Multifactor explanations of asset pricing anomalies." The Journal of Finance 51.1 (1996): 55-84. 
Fama, Eugene F., and Kenneth R. French. "The CAPM is wanted, dead or alive." The Journal of Finance 51.5 (1996): 1947-1958.

Fama, Eugene F., and Kenneth R. French. "Value versus growth: The international evidence." The Journal of Finance 53.6 (1998): 1975-1999.

Fama, Eugene F., and Kenneth R. French. "The equity premium." The Journal of Finance 57.2 (2002): 637-659.

Fama, Eugene F., and Kenneth R. French. "The capital asset pricing model: Theory and evidence." Journal of Economic Perspectives 18.3 (2004): 25-46.

Fama, Eugene F., and James D. MacBeth. "Risk, return, and equilibrium: Empirical tests." Journal of Political Economy 81.3 (1973): 607-636.

Fang, Hsing, and Tsong-Yue Lai. "Co-kurtosis and Capital Asset Pricing." Financial Review 32.2 (1997): 293-307.

Friend, Irwin, and Randolph Westerfield. "Co-skewness and capital asset pricing." The Journal of Finance 35.4 (1980): 897-913.

Freeman, Mark C., and Cherif Guermat. "The conditional relationship between beta and returns: A reassessment." Journal of Business Finance \& Accounting 33.7-8 (2006): 1213-1239.

Gibbons, Michael R, "Multivariate tests of financial models." Journal of Financial Economics 10 (1982): 3-27.

Hung, Chi-Hsiou. "Return Predictability of Higher-Moment CAPM Market Models." Journal of Business Finance \& Accounting 35.7-8 (2008): 998-1022.

Isakov, Dusan. "Is beta still alive? Conclusive evidence from the Swiss stock market." The European Journal of Finance 5.3 (1999): 202-212.

Jagannathan, Ravi, and Zhenyu Wang. "The conditional CAPM and the cross-section of expected returns." The Journal of Finance 51.1 (1996): 3-53.

Kahneman, D., and Tversky, A., "Prospect theory: An analysis of decision under risk." Econometrica 47.2 (1979): 263-292.

Kim, Dongcheol. "The errors in the variables problem in the cross-section of expected stock returns." The Journal of Finance 50.5 (1995): 1605-1634.

Kraus, Alan, and Robert H. Litzenberger. "Skewness preference and the valuation of risk assets." The Journal of Finance 31.4 (1976): 1085-1100.

Lai, Tsong-Yue, and Mark Hoven Stohs. "Yes, CAPM is dead." International Journal of Business 20.2 (2015): 144.

Lewellen, Jonathan, and Stefan Nagel, "The conditional CAPM does not explain assetpricing annomalies" Journal of Financial Economics 82 (2006): 289-314. 
Limmack, Robin J., and C. W. R. Ward. "The October 1987 stock market crash: An exploratory analysis of share price models." Journal of Banking \& Finance 14.2-3 (1990): 273-289..

Lintner, John. "The valuation of risk assets and the selection of risky investments in stock portfolios and capital budgets." Stochastic Optimization Models in Finance (1975): 131155.

Malloch, H., Philip, R., \& Satchell, S. "Decomposing the bias in time-series estimates of betas." Applied Economics 48 (2016): 4291-4298.

Mossin, Jan. "Equilibrium in a capital asset market." Econometrica: Journal of the Econometric Society (1966): 768-783.

Newey, W. K., and West, K. D., “A simple, positive semi-definite, heteroskedasticity and autocorrelation consistent covariance matrix.” Econometrica 55 (1987): 703-708.

Newey, W. K., and West, K. D., “Automatic lag selection in covariance estimation." Review of Economics Studies 61 (1994): 631-654.

Officer, Robert Rupert. "The distribution of stock returns." Journal of the American Statistical Association 67.340 (1972): 807-812.

Penman, Stephen H. "The distribution of earnings news over time and seasonalities in aggregate stock returns." Journal of Financial Economics 18.2 (1987): 199-228.

Pettengill, Glenn N., Sridhar Sundaram, and Ike Mathur. "The conditional relation between beta and returns." Journal of Financial and Quantitative Analysis 30.1 (1995): 101-116.

Ray, Surajit, N. Eugene Savin, and Ashish Tiwari. "Testing the CAPM revisited." Journal of Empirical Finance 16.5 (2009): 721-733.

Riyath, M. I. M., and P. D. Nimal. "Comparative Study on Asset Pricing Models in Explaining Cross Sectional Variation of Stock Returns in the Colombo Stock Exchange." 13th International Conference on Business Management (2016).

Roll, Richard. "A critique of the asset pricing theory's tests Part I: On past and potential testability of the theory." Journal of Financial Economics 4.2 (1977): 129-176.

Rosenberg, B., Reid, K., \& Lan, S. R. Persuasive evidence of market inefficiency. Journal of Porfolio Management, 11 (1985): 9-17.

Samarakoon, Lalith P. "The cross-section of expected stock returns in Sri Lanka." Sri Lankan Journal of Management, 2.3 (1997): 234-250.

Sauer, Andreas, and Austin Murphy. "An empirical comparison of alternative models of capital asset pricing in Germany." Journal of Banking \& Finance 16.1 (1992): 183-196.

Schwert, G. William. "Size and stock returns, and other empirical regularities." Journal of Financial Economics 12.1 (1983): 3-12.

Sharpe, William F. "Capital asset prices: A theory of market equilibrium under conditions of risk." The Journal of Finance 19.3 (1964): 425-442. 
Shahi, C. \& Shaffer, S. CAPM and the changing distribution of historical returns, Applied Economics Letters, 24:9, (2017): 639-642.

Shanken, Jay. "On the estimation of beta-pricing models." The Review of Financial Studies 5.1 (1992): 1-33.

Shanken, Jay, and Guofu Zhou. "Estimating and testing beta pricing models: Alternative methods and their performance in simulations." Journal of Financial Economics 84.1 (2007): 40-86.

Stambaugh, Robert F. "On the exclusion of assets from tests of the two-parameter model: A sensitivity analysis." Journal of Financial Economics 10.3 (1982): 237-268.

Tang, Gordon YN, and Wai C. Shum. "The conditional relationship between beta and returns: recent evidence from international stock markets." International Business Review 12.1 (2003): 109-126.

Thilakarathne, P. M. C and Jayasinghe, Y. N. "Validity of beta in explaining expected returns of securities listed in the Colombo Stock Exchange-Sri Lanka." Journal of Finance and Accounting 2 (2014); 95-100.

Vendrame, Vasco, Jon Tucker, and Cherif Guermat. "Some extensions of the CAPM for individual assets." International Review of Financial Analysis 44 (2016): 78-85. 


\section{Appendices}

\section{A.1 Tables}

Table A1: Correlation of excess stock returns with the market excess return

\begin{tabular}{|c|c|c|c|c|c|c|c|c|}
\hline Firm & Correlation & t stat & Firm & Correlation & t stat & Firm & Correlation & t stat \\
\hline 1 & 0.7407 & 32.7822 & 26 & 0.4318 & 14.2342 & 51 & 0.4075 & 13.2665 \\
\hline 2 & 0.6987 & 29.0373 & 27 & 0.4675 & 15.7243 & 52 & 0.5098 & 17.6192 \\
\hline 3 & 0.6608 & 26.1742 & 28 & 0.4233 & 13.8932 & 53 & 0.5469 & 19.4224 \\
\hline 4 & 0.5594 & 20.0677 & 29 & 0.3504 & 11.1222 & 54 & 0.3983 & 12.9111 \\
\hline 5 & 0.4662 & 15.6698 & 30 & 0.4553 & 15.2062 & 55 & 0.3727 & 11.9434 \\
\hline 6 & 0.4799 & 16.2652 & 31 & 0.4331 & 14.2850 & 56 & 0.4901 & 16.7192 \\
\hline 7 & 0.3481 & 11.0409 & 32 & 0.4458 & 14.8090 & 57 & 0.2722 & 8.4090 \\
\hline 8 & 0.3978 & 12.8900 & 33 & 0.4095 & 13.3449 & 58 & 0.5579 & 19.9872 \\
\hline 9 & 0.5086 & 17.5627 & 34 & 0.2575 & 7.9217 & 59 & 0.4866 & 16.5583 \\
\hline 10 & 0.4543 & 15.1626 & 35 & 0.5005 & 17.1867 & 60 & 0.6322 & 24.2574 \\
\hline 11 & 0.3922 & 12.6760 & 36 & 0.3778 & 12.1303 & 61 & 0.6718 & 26.9658 \\
\hline 12 & 0.4952 & 16.9485 & 37 & 0.5746 & 20.8731 & 62 & 0.3680 & 11.7667 \\
\hline 13 & 0.3508 & 11.1376 & 38 & 0.3234 & 10.1601 & 63 & 0.4752 & 16.0566 \\
\hline 14 & 0.5579 & 19.9872 & 39 & 0.4635 & 15.5524 & 64 & 0.4988 & 17.1099 \\
\hline 15 & 0.5368 & 18.9173 & 40 & 0.4625 & 15.5102 & 65 & 0.4752 & 16.0566 \\
\hline 16 & 0.6738 & 27.1151 & 41 & 0.4335 & 14.3044 & 66 & 0.5036 & 17.3307 \\
\hline 17 & 0.5091 & 17.5866 & 42 & 0.5055 & 17.4189 & 67 & 0.2618 & 8.0655 \\
\hline 18 & 0.2181 & 6.6429 & 43 & 0.2438 & 7.4747 & 68 & 0.5574 & 19.9620 \\
\hline 19 & 0.4556 & 15.2169 & 44 & 0.4185 & 13.6985 & 69 & 0.6068 & 22.6986 \\
\hline 20 & 0.5330 & 18.7310 & 45 & 0.4132 & 13.4916 & 70 & 0.4314 & 14.2157 \\
\hline 21 & 0.4937 & 16.8779 & 46 & 0.5436 & 19.2549 & 71 & 0.3630 & 11.5845 \\
\hline 22 & 0.5543 & 19.7998 & 47 & 0.5440 & 19.2772 & 72 & 0.3065 & 9.5724 \\
\hline 23 & 0.3891 & 12.5578 & 48 & 0.3639 & 11.6174 & 73 & 0.3465 & 10.9824 \\
\hline 24 & 0.7071 & 29.7330 & 49 & 0.4124 & 13.4611 & 74 & 0.4157 & 13.5897 \\
\hline 25 & 0.2896 & 8.9964 & 50 & 0.4343 & 14.3346 & & & \\
\hline
\end{tabular}


Table A2: Summary statistics for the stock returns

\begin{tabular}{|c|c|c|c|c|c|}
\hline Firm & Mean & $\begin{array}{l}\text { Std. } \\
\text { Dev. }\end{array}$ & Skewness & Kurtosis & JB stat \\
\hline 1 & $0.08 \%$ & 0.0469 & 1.4812 & 14.2945 & 5033.26 \\
\hline 2 & $0.01 \%$ & 0.0461 & 1.6507 & 11.9689 & 3372.02 \\
\hline 3 & $0.01 \%$ & 0.0460 & 2.1228 & 20.6875 & 12214.65 \\
\hline 4 & $0.09 \%$ & 0.0706 & 1.2880 & 9.7339 & 1918.99 \\
\hline 5 & $-0.12 \%$ & 0.0866 & 1.5377 & 11.4564 & 2989.08 \\
\hline 6 & $-0.34 \%$ & 0.0594 & 0.0567 & 4.5398 & 88.00 \\
\hline 7 & $-0.22 \%$ & 0.0889 & 0.6223 & 9.1069 & 1433.98 \\
\hline 8 & $-0.04 \%$ & 0.0683 & 0.7149 & 6.5479 & 540.17 \\
\hline 9 & $-0.23 \%$ & 0.0707 & 0.5522 & 6.9433 & 619.06 \\
\hline 10 & $-0.12 \%$ & 0.0702 & 0.7656 & 6.9107 & 651.13 \\
\hline 11 & $-0.30 \%$ & 0.0775 & 2.3065 & 26.9530 & 21966.41 \\
\hline 12 & $-0.28 \%$ & 0.0645 & 0.8180 & 7.6140 & 884.72 \\
\hline 13 & $-0.13 \%$ & 0.1121 & 1.8891 & 24.2669 & 17223.76 \\
\hline 14 & $0.03 \%$ & 0.0395 & 1.6012 & 17.9650 & 8646.08 \\
\hline 15 & $0.03 \%$ & 0.0500 & 0.4744 & 6.3552 & 448.81 \\
\hline 16 & $0.04 \%$ & 0.0410 & 0.4586 & 11.2417 & 2538.64 \\
\hline 17 & $0.30 \%$ & 0.0609 & 2.0344 & 15.1371 & 6049.27 \\
\hline 18 & $0.15 \%$ & 0.1281 & -0.2194 & 309.7410 & 3473497.00 \\
\hline 19 & $0.21 \%$ & 0.0858 & 1.8245 & 12.4436 & 3783.78 \\
\hline 20 & $0.13 \%$ & 0.0378 & -0.3728 & 16.9751 & 7230.50 \\
\hline 21 & $0.17 \%$ & 0.0544 & 1.4110 & 11.0581 & 2691.12 \\
\hline 22 & $0.01 \%$ & 0.0578 & 1.0311 & 7.9348 & 1056.01 \\
\hline 23 & $0.18 \%$ & 0.0367 & 0.9088 & 9.1260 & 1507.37 \\
\hline 24 & $0.12 \%$ & 0.0401 & 0.9579 & 10.6690 & 2306.72 \\
\hline
\end{tabular}


Table A2: Cont...

\begin{tabular}{|c|c|c|c|c|c|}
\hline Firm & Mean & $\begin{array}{l}\text { Std. } \\
\text { Dev. }\end{array}$ & Skewness & Kurtosis & JB stat \\
\hline 25 & $0.20 \%$ & 0.0431 & 0.6560 & 17.6411 & 7977.07 \\
\hline 26 & $0.12 \%$ & 0.0756 & 1.1854 & 9.8465 & 1937.98 \\
\hline 27 & $-0.08 \%$ & 0.0658 & 0.0723 & 11.5388 & 2692.40 \\
\hline 28 & $-0.23 \%$ & 0.0806 & 1.7278 & 18.1874 & 8955.85 \\
\hline 29 & $-0.19 \%$ & 0.0735 & 0.6411 & 7.3967 & 774.33 \\
\hline 30 & $-0.13 \%$ & 0.0675 & 0.4138 & 6.7785 & 552.35 \\
\hline 31 & $-0.06 \%$ & 0.0944 & 1.4835 & 9.6770 & 1970.83 \\
\hline 32 & $0.08 \%$ & 0.0748 & 1.0756 & 8.2797 & 1199.89 \\
\hline 33 & $-0.03 \%$ & 0.0721 & 1.4941 & 11.3344 & 2893.94 \\
\hline 34 & $-0.13 \%$ & 0.1009 & 1.3189 & 130.3279 & 598764.30 \\
\hline 35 & $-0.16 \%$ & 0.0685 & 1.6692 & 10.8430 & 2682.29 \\
\hline 36 & $0.24 \%$ & 0.0524 & 0.4379 & 9.0848 & 1395.16 \\
\hline 37 & $0.12 \%$ & 0.0412 & 1.5586 & 11.6154 & 3098.84 \\
\hline 38 & $0.08 \%$ & 0.0520 & -1.0500 & 37.8133 & 44904.47 \\
\hline 39 & $0.11 \%$ & 0.0471 & 0.4519 & 7.4061 & 746.86 \\
\hline 40 & $0.04 \%$ & 0.0585 & 2.8307 & 29.3348 & 26785.65 \\
\hline 41 & $-0.03 \%$ & 0.0466 & 0.7350 & 10.5418 & 2179.55 \\
\hline 42 & $0.10 \%$ & 0.0514 & 0.7022 & 8.3491 & 1129.12 \\
\hline 43 & $0.14 \%$ & 0.0921 & -0.1767 & 212.0683 & 1613616.00 \\
\hline 44 & $0.06 \%$ & 0.0580 & 1.0825 & 9.8010 & 1880.56 \\
\hline 45 & $0.00 \%$ & 0.0443 & 0.5354 & 7.2774 & 717.77 \\
\hline 46 & $-0.04 \%$ & 0.0681 & 1.3483 & 8.9758 & 1586.73 \\
\hline 47 & $-0.07 \%$ & 0.0698 & 1.4442 & 9.7743 & 2002.13 \\
\hline 48 & $0.04 \%$ & 0.0689 & 0.2867 & 13.0263 & 3723.21 \\
\hline 49 & $0.15 \%$ & 0.0923 & 2.0832 & 16.4829 & 7351.80 \\
\hline 50 & $0.26 \%$ & 0.0938 & 2.3918 & 19.2098 & 10544.96 \\
\hline 51 & $-0.01 \%$ & 0.0702 & 1.0162 & 8.1816 & 1143.69 \\
\hline 52 & $0.14 \%$ & 0.0674 & 1.2237 & 8.6454 & 1397.68 \\
\hline 53 & $-0.03 \%$ & 0.0801 & 2.7023 & 21.7169 & 14011.00 \\
\hline 54 & $0.02 \%$ & 0.0574 & 2.9705 & 45.6163 & 68349.18 \\
\hline 55 & $-0.05 \%$ & 0.0683 & 0.4613 & 13.1711 & 3850.50 \\
\hline
\end{tabular}


Table A2: Cont...

\begin{tabular}{|c|c|c|c|c|c|}
\hline Firm & Mean & $\begin{array}{l}\text { Std. } \\
\text { Dev. }\end{array}$ & Skewness & Kurtosis & JB stat \\
\hline 56 & $-0.01 \%$ & 0.0741 & 1.2715 & 10.0255 & 2060.83 \\
\hline 57 & $0.27 \%$ & 0.0747 & 1.1681 & 65.8614 & 146079.50 \\
\hline 58 & $0.03 \%$ & 0.0395 & 1.6012 & 17.9650 & 8646.08 \\
\hline 59 & $0.07 \%$ & 0.0522 & 1.4439 & 10.5553 & 2415.18 \\
\hline 60 & $-0.03 \%$ & 0.0400 & 1.7479 & 16.5002 & 7179.37 \\
\hline 61 & $0.00 \%$ & 0.0443 & 1.1789 & 11.3284 & 2765.87 \\
\hline 62 & $0.09 \%$ & 0.0519 & 0.7064 & 8.1754 & 1062.47 \\
\hline 63 & $0.09 \%$ & 0.0579 & 0.3352 & 11.4973 & 2682.14 \\
\hline 64 & $0.09 \%$ & 0.0519 & 0.7063 & 8.1754 & 1062.49 \\
\hline 65 & $0.09 \%$ & 0.0579 & 0.3352 & 11.4973 & 2682.14 \\
\hline 66 & $0.11 \%$ & 0.0570 & 0.4098 & 20.5040 & 11335.70 \\
\hline 67 & $0.07 \%$ & 0.1222 & 1.2389 & 257.7111 & 2395296.00 \\
\hline 68 & $-0.01 \%$ & 0.0445 & 1.2800 & 9.5278 & 1815.04 \\
\hline 69 & $-0.10 \%$ & 0.0628 & 0.1448 & 9.9226 & 1772.20 \\
\hline 70 & $-0.02 \%$ & 0.0703 & 0.3482 & 6.8698 & 570.74 \\
\hline 71 & $0.02 \%$ & 0.0813 & -0.1134 & 12.6505 & 3440.02 \\
\hline 72 & $-0.09 \%$ & 0.1070 & -8.5350 & 187.3852 & 1265846.00 \\
\hline 73 & $-0.19 \%$ & 0.0699 & 0.7029 & 10.0639 & 1915.07 \\
\hline 74 & $-0.14 \%$ & 0.0745 & 0.7094 & 7.3496 & 772.74 \\
\hline Mkt & $0.07 \%$ & 0.0263 & 0.6953 & 8.5969 & 1227.81 \\
\hline
\end{tabular}

Note: This table shows summary of excess returns. JB stat column shows the test statistics for the Jarque-Bera normality test. All these test statistics are significant indicating that returns are not normally distributed. 
Table A3: Summary of estimates for the 17-year period

\begin{tabular}{ccccccc}
\hline \hline \multirow{2}{*}{ Year } & \multicolumn{2}{c}{ Beta } & \multicolumn{2}{c}{ Gamma } & \multicolumn{2}{c}{ Delta } \\
\cline { 2 - 6 } & Maximum & Minimum & Maximum & Minimum & Maximum & Minimum \\
\hline 2000 & 2.4521 & -1.2443 & 24.0421 & -58.1385 & 1308.4120 & -825.3348 \\
2001 & 2.7765 & 0.2939 & 17.7623 & 1.1601 & 99.1653 & 5.5966 \\
2002 & 2.3165 & -0.1035 & 37.7754 & -17.0842 & 664.0376 & -104.4101 \\
2003 & 1.8186 & 0.1464 & 0.6835 & -16.0654 & 235.8253 & 27.3067 \\
2004 & 2.0879 & -0.3430 & 14.5244 & -7.5655 & 324.0003 & -72.2851 \\
2005 & 1.8226 & 0.0898 & 3.7516 & -37.0456 & 649.3086 & 24.3296 \\
2006 & 2.3474 & 0.1265 & 40.8820 & -11.1436 & 455.2237 & -18.6599 \\
2007 & 3.2842 & -0.1006 & 22.4285 & -50.2987 & 2077.7940 & -29.2873 \\
2008 & 2.5034 & -0.0290 & 1.9825 & -26.4593 & 230.8908 & -5.3654 \\
2009 & 1.7221 & 0.0449 & 25.7511 & -2.8122 & 255.6264 & -22.5095 \\
2010 & 3.0705 & -0.3232 & 85.9203 & -10.9722 & 1263.8500 & -87.3830 \\
2011 & 3.2848 & -0.1671 & 40.5012 & -29.2050 & 1733.9670 & 14.3916 \\
2012 & 3.8500 & 0.0163 & 32.9060 & -13.0442 & 1107.0010 & -25.9923 \\
2013 & 2.6751 & -0.0622 & 57.0589 & -57.6054 & 1854.3860 & -143.3809 \\
2014 & 3.5060 & -0.6249 & 32.0654 & -87.0365 & 4346.9000 & -624.2718 \\
2015 & 3.2368 & -0.2998 & 45.2601 & -49.5508 & 3580.6420 & -1303.3500 \\
2016 & 3.4759 & 0.0796 & 28.4544 & -84.6127 & 2522.8610 & -209.0743 \\
\hline
\end{tabular}


Table A4: Summary of Beta estimates for each firm

\begin{tabular}{|c|c|c|c|c|c|c|c|}
\hline Firm & Mean & Maximum & Minimum & Firm & Mean & Maximum & Minimum \\
\hline 1 & 1.2532 & 2.2597 & 0.5009 & 38 & 0.7505 & 1.6791 & 0.0449 \\
\hline 2 & 1.1605 & 1.8709 & 0.6419 & 39 & 1.0249 & 2.6776 & 0.0642 \\
\hline 3 & 1.0888 & 2.1749 & 0.2533 & 40 & 0.9639 & 1.5755 & -1.2443 \\
\hline 4 & 1.5169 & 2.4102 & 0.7716 & 41 & 0.8337 & 2.1711 & 0.3329 \\
\hline 5 & 1.5150 & 2.3671 & 0.4705 & 42 & 1.0591 & 1.4401 & 0.2050 \\
\hline 6 & 1.3204 & 2.2542 & 0.4988 & 43 & 0.9238 & 1.7148 & -0.0290 \\
\hline 7 & 1.1176 & 2.9631 & -0.3430 & 44 & 0.9035 & 1.6397 & 0.2712 \\
\hline 8 & 1.2490 & 2.8005 & 0.4268 & 45 & 0.6468 & 1.2972 & 0.2776 \\
\hline 9 & 1.4086 & 2.4769 & 0.5893 & 46 & 1.3925 & 2.0811 & 0.8304 \\
\hline 10 & 1.1729 & 2.1819 & 0.1923 & 47 & 1.5008 & 3.2848 & 0.6248 \\
\hline 11 & 1.5282 & 3.5060 & 0.1761 & 48 & 1.0395 & 2.2425 & 0.2058 \\
\hline 12 & 1.2076 & 2.5034 & 0.4308 & 49 & 1.4960 & 3.2368 & -0.3232 \\
\hline 13 & 1.6381 & 2.8447 & 0.3850 & 50 & 1.6576 & 3.2842 & 0.0666 \\
\hline 14 & 0.8512 & 1.7156 & 0.3232 & 51 & 1.0695 & 1.9772 & 0.1271 \\
\hline 15 & 1.0550 & 1.7579 & 0.4578 & 52 & 1.2596 & 2.2255 & 0.1634 \\
\hline 16 & 1.0116 & 1.8044 & 0.4527 & 53 & 1.6130 & 2.7766 & 0.8262 \\
\hline 17 & 1.2320 & 2.4083 & 0.5998 & 54 & 1.0095 & 1.6240 & 0.4983 \\
\hline 18 & 0.9781 & 1.5686 & 0.5729 & 55 & 1.1633 & 2.4918 & 0.2939 \\
\hline 19 & 1.5576 & 2.9289 & 0.1130 & 56 & 1.4205 & 2.1401 & 0.9084 \\
\hline 20 & 0.8271 & 1.2936 & 0.3052 & 57 & 0.6896 & 2.3474 & -0.6249 \\
\hline 21 & 1.1151 & 1.8142 & 0.3514 & 58 & 0.8512 & 1.7156 & 0.3232 \\
\hline 22 & 1.1819 & 1.8187 & 0.3687 & 59 & 1.0078 & 1.4609 & 0.1464 \\
\hline 23 & 0.6251 & 2.4005 & -0.1006 & 60 & 0.8896 & 1.7950 & 0.2709 \\
\hline 24 & 1.0858 & 1.7938 & 0.4717 & 61 & 1.1685 & 1.7114 & 0.8731 \\
\hline 25 & 0.5335 & 1.3911 & -0.0993 & 62 & 0.8118 & 1.4593 & -0.1036 \\
\hline 26 & 1.0755 & 1.7655 & 0.1900 & 63 & 1.0382 & 2.2232 & 0.3912 \\
\hline 27 & 1.1567 & 2.1768 & 0.3850 & 64 & 0.9893 & 1.4593 & 0.5016 \\
\hline 28 & 1.4761 & 3.8501 & 0.3073 & 65 & 1.0382 & 2.2232 & 0.3912 \\
\hline 29 & 0.8588 & 1.9000 & -0.0622 & 66 & 1.1546 & 1.7157 & 0.5296 \\
\hline 30 & 1.1521 & 2.6538 & -0.1978 & 67 & 1.2321 & 3.0705 & 0.4007 \\
\hline 31 & 1.4957 & 2.5883 & 0.8456 & 68 & 0.8975 & 1.5049 & 0.4789 \\
\hline 32 & 1.2750 & 2.2902 & 0.1440 & 69 & 1.3265 & 2.0879 & 0.3082 \\
\hline 33 & 1.1658 & 2.6521 & 0.4054 & 70 & 1.1073 & 2.4178 & 0.2629 \\
\hline 34 & 1.1562 & 2.5511 & -0.1671 & 71 & 1.1228 & 2.1826 & 0.0521 \\
\hline 35 & 1.1813 & 2.0444 & 0.4405 & 72 & 1.4611 & 2.5823 & 0.2375 \\
\hline 36 & 0.8225 & 1.4890 & 0.0913 & 73 & 0.9818 & 2.0727 & -0.1067 \\
\hline 37 & 0.8538 & 1.2949 & 0.3466 & 74 & 1.2022 & 2.2786 & 0.4415 \\
\hline
\end{tabular}


Table A5: Summary of Gamma estimates for each firm

\begin{tabular}{|c|c|c|c|c|c|c|c|}
\hline Firm & Mean & Maximum & Minimum & Firm & Mean & Maximum & Minimum \\
\hline 1 & -5.8748 & 25.7511 & -30.8359 & 38 & -4.1497 & 8.1200 & -30.2391 \\
\hline 2 & 2.1951 & 21.3027 & -21.1274 & 39 & -5.8437 & 22.7637 & -60.7236 \\
\hline 3 & 0.0158 & 24.8879 & -25.6171 & 40 & -2.3889 & 24.0421 & -22.8136 \\
\hline 4 & -3.1097 & 25.3790 & -45.0726 & 41 & -4.5838 & 12.4555 & -34.1050 \\
\hline 5 & -7.6441 & 31.7995 & -63.1894 & 42 & -3.5915 & 14.4406 & -18.4933 \\
\hline 6 & -5.0808 & 28.4544 & -63.4273 & 43 & -1.7007 & 26.5332 & -50.2987 \\
\hline 7 & -8.1487 & 18.0102 & -48.3791 & 44 & -0.4181 & 43.1615 & -57.0288 \\
\hline 8 & 1.0116 & 29.4899 & -22.2140 & 45 & -2.0417 & 12.8844 & -28.1457 \\
\hline 9 & -3.4456 & 45.2602 & -36.3391 & 46 & -4.0955 & 18.4038 & -50.3931 \\
\hline 10 & -11.7633 & 13.8430 & -84.6127 & 47 & -1.9806 & 40.5012 & -47.6704 \\
\hline 11 & -9.0215 & 25.5480 & -62.3217 & 48 & 3.3475 & 57.0589 & -11.0710 \\
\hline 12 & -0.6856 & 30.3074 & -40.8469 & 49 & -5.0454 & 24.6729 & -48.3919 \\
\hline 13 & -11.4327 & 40.8820 & -75.3869 & 50 & -1.3744 & 45.0715 & -66.1713 \\
\hline 14 & 1.7719 & 35.0372 & -13.6398 & 51 & -5.0101 & 17.0335 & -32.0175 \\
\hline 15 & -0.0437 & 20.8599 & -18.7076 & 52 & -2.9075 & 32.0654 & -39.2869 \\
\hline 16 & -1.9187 & 23.0281 & -22.1740 & 53 & 0.9931 & 28.5149 & -38.6423 \\
\hline 17 & -4.1358 & 46.5286 & -33.9183 & 54 & -5.1976 & 12.9091 & -52.6719 \\
\hline 18 & -0.6061 & 14.5149 & -14.6838 & 55 & -6.9938 & 18.1645 & -58.1385 \\
\hline 19 & -1.7753 & 25.1605 & -28.6478 & 56 & -1.5801 & 21.1223 & -26.5592 \\
\hline 20 & -7.0214 & 7.7567 & -46.6623 & 57 & -4.9178 & 21.3295 & -35.8904 \\
\hline 21 & -3.6287 & 23.5455 & -59.0704 & 58 & 1.7719 & 35.0372 & -13.6398 \\
\hline 22 & -1.8914 & 20.1071 & -20.0761 & 59 & -0.6435 & 33.8233 & -32.4478 \\
\hline 23 & -4.6796 & 9.3414 & -57.6054 & 60 & 0.1286 & 14.8066 & -11.7219 \\
\hline 24 & -4.3353 & 17.8759 & -39.2207 & 61 & -0.6119 & 23.7798 & -19.4277 \\
\hline 25 & -4.3225 & 13.8269 & -36.3547 & 62 & -5.2840 & 12.4470 & -27.9753 \\
\hline 26 & -2.8601 & 25.6664 & -47.7266 & 63 & -2.8237 & 14.7211 & -35.2567 \\
\hline 27 & -5.2712 & 37.1824 & -37.0456 & 64 & -5.0442 & 12.4470 & -27.9753 \\
\hline 28 & -0.4980 & 33.2142 & -47.8053 & 65 & -2.8237 & 14.7211 & -35.2567 \\
\hline 29 & -10.9971 & 13.1516 & -72.5252 & 66 & -3.8441 & 20.7761 & -51.8976 \\
\hline 30 & -4.9023 & 22.4107 & -41.8273 & 67 & -0.6517 & 85.9203 & -51.2243 \\
\hline 31 & -3.1821 & 24.0930 & -49.5508 & 68 & -3.1712 & 9.1170 & -16.7966 \\
\hline 32 & 2.7988 & 31.8615 & -27.3127 & 69 & -3.2016 & 17.6167 & -38.6185 \\
\hline 33 & 0.8171 & 17.4333 & -30.1225 & 70 & -5.7028 & 24.8050 & -41.0369 \\
\hline 34 & 0.0998 & 25.6465 & -29.2050 & 71 & 4.7338 & 37.7754 & -22.4955 \\
\hline 35 & 1.3761 & 40.9568 & -17.9644 & 72 & -1.6052 & 32.4369 & -20.6863 \\
\hline 36 & -5.7717 & 16.8618 & -35.9374 & 73 & -5.9070 & 19.6068 & -87.0365 \\
\hline 37 & -0.8740 & 13.8262 & -27.6667 & 74 & -4.3322 & 19.9256 & -46.1193 \\
\hline
\end{tabular}


Table A6: Summary of Delta estimates for each firm

\begin{tabular}{|c|c|c|c|c|c|c|c|}
\hline Firm & Mean & Maximum & Minimum & Firm & Mean & Maximum & Minimum \\
\hline 1 & 493.89 & 2107.59 & 66.12 & 38 & 391.18 & 1722.30 & -15.24 \\
\hline 2 & 449.65 & 2104.98 & 61.86 & 39 & 624.76 & 3538.03 & 20.58 \\
\hline 3 & 462.80 & 1590.66 & 58.60 & 40 & 376.61 & 1750.20 & -825.33 \\
\hline 4 & 559.26 & 1577.50 & 56.93 & 41 & 388.80 & 1936.67 & 23.42 \\
\hline 5 & 586.11 & 2416.25 & 8.90 & 42 & 461.85 & 1654.33 & 27.57 \\
\hline 6 & 624.68 & 2812.58 & 32.15 & 43 & 473.13 & 1470.89 & 20.79 \\
\hline 7 & 514.10 & 2061.23 & -42.43 & 44 & 419.85 & 2061.10 & 46.36 \\
\hline 8 & 518.68 & 2484.17 & 26.22 & 45 & 290.07 & 1170.52 & 30.49 \\
\hline 9 & 558.12 & 1738.66 & 36.21 & 46 & 556.88 & 2418.56 & 41.39 \\
\hline 10 & 390.52 & 1262.55 & 5.14 & 47 & 548.38 & 1733.97 & -87.38 \\
\hline 11 & 846.41 & 4346.90 & 17.25 & 48 & 413.88 & 2638.40 & -58.47 \\
\hline 12 & 383.97 & 1727.00 & -140.17 & 49 & 717.14 & 3580.64 & -80.14 \\
\hline 13 & 576.98 & 1543.19 & -22.51 & 50 & 780.74 & 3007.45 & 0.11 \\
\hline 14 & 393.95 & 2018.43 & 21.53 & 51 & 376.14 & 1749.72 & -135.48 \\
\hline 15 & 469.53 & 2050.73 & 26.57 & 52 & 406.55 & 1552.31 & -111.79 \\
\hline 16 & 445.87 & 1836.83 & 52.72 & 53 & 686.58 & 2523.71 & 97.78 \\
\hline 17 & 548.33 & 2019.78 & 28.55 & 54 & 461.42 & 2525.04 & 15.88 \\
\hline 18 & 433.44 & 1842.06 & 58.38 & 55 & 555.25 & 1376.53 & 5.60 \\
\hline 19 & 576.54 & 1865.13 & -45.61 & 56 & 581.78 & 1958.17 & 63.93 \\
\hline 20 & 413.16 & 1744.43 & -7.43 & 57 & 132.65 & 1235.00 & -1303.35 \\
\hline 21 & 499.96 & 2234.16 & 21.56 & 58 & 393.95 & 2018.43 & 21.53 \\
\hline 22 & 448.63 & 1449.66 & 24.94 & 59 & 463.60 & 2064.84 & 38.35 \\
\hline 23 & 268.89 & 1854.39 & -29.29 & 60 & 317.09 & 1349.05 & 68.31 \\
\hline 24 & 537.23 & 2436.01 & 44.97 & 61 & 539.91 & 2655.91 & 41.31 \\
\hline 25 & 287.33 & 1102.25 & 13.32 & 62 & 374.97 & 1294.63 & -104.41 \\
\hline 26 & 205.68 & 767.57 & -598.15 & 63 & 449.72 & 2610.42 & 50.83 \\
\hline 27 & 541.59 & 2728.21 & -18.66 & 64 & 411.01 & 1294.63 & 25.45 \\
\hline 28 & 627.05 & 2429.32 & 22.56 & 65 & 449.72 & 2610.42 & 50.83 \\
\hline 29 & 436.60 & 3447.15 & -347.78 & 66 & 504.05 & 1906.53 & 24.50 \\
\hline 30 & 431.53 & 1218.91 & 43.44 & 67 & 528.66 & 1703.02 & 27.31 \\
\hline 31 & 568.00 & 2273.36 & 98.98 & 68 & 346.91 & 1107.59 & 55.08 \\
\hline 32 & 444.87 & 1283.71 & -209.07 & 69 & 557.64 & 2607.85 & 58.10 \\
\hline 33 & 440.09 & 1570.74 & 63.84 & 70 & 331.12 & 1297.49 & -231.25 \\
\hline 34 & 516.11 & 2250.32 & -15.01 & 71 & 419.94 & 2025.96 & -143.38 \\
\hline 35 & 358.79 & 1051.19 & 63.37 & 72 & 540.00 & 1646.48 & 24.38 \\
\hline 36 & 380.54 & 976.89 & -5.37 & 73 & 490.08 & 2541.82 & -72.29 \\
\hline 37 & 355.46 & 1308.37 & 22.10 & 74 & 495.64 & 1689.89 & 33.37 \\
\hline
\end{tabular}


Table A7: Estimates of risk premium in each year

\begin{tabular}{ccccccc}
\hline \hline Year & $\alpha$ & $\lambda_{B}$ & $\lambda_{v}$ & $\lambda_{\delta}$ & Adj $\mathrm{R}^{2}$ & F- Stat \\
\hline 2001 & 0.002196 & 0.004959 & -0.000003 & -0.000012 & 0.0258 & 0.1870 \\
2002 & 0.002225 & -0.014097 & -0.003685 & 0.000986 & 0.0689 & $0.0462^{* *}$ \\
2003 & 0.000376 & -0.001852 & 0.000101 & 0.000007 & -0.0108 & 0.5318 \\
2004 & 0.005041 & 0.001736 & -0.000178 & -0.000031 & -0.0340 & 0.1990 \\
2005 & 0.002518 & -0.004243 & 0.000128 & 0.000004 & 0.0283 & 0.1733 \\
2006 & 0.003528 & 0.010349 & -0.000289 & -0.000038 & 0.0417 & 0.1135 \\
2007 & -0.001654 & -0.000164 & -0.000871 & 0.000065 & 0.1134 & $0.0095^{* *}$ \\
2008 & -0.007615 & -0.001520 & 0.000157 & -0.000002 & 0.0536 & $0.0771^{*}$ \\
2009 & 0.013237 & -0.006731 & -0.001439 & -0.000093 & 0.0018 & 0.3784 \\
2010 & 0.010399 & 0.007171 & -0.002081 & 0.000199 & 0.0385 & 0.1259 \\
2011 & -0.000403 & -0.003067 & -0.000042 & -0.000001 & 0.0835 & 0.0280 \\
2012 & -0.000387 & -0.008870 & 0.000039 & 0.000010 & 0.1550 & $0.002^{* *}$ \\
2013 & -0.000577 & 0.001337 & -0.000002 & -0.000010 & 0.0552 & $0.073^{*}$ \\
2014 & 0.003949 & -0.004902 & 0.000038 & 0.000008 & 0.064 & $0.0546^{*}$ \\
2015 & -0.001445 & 0.001278 & 0.000024 & -0.000002 & 0.0540 & $0.0761^{*}$ \\
2016 & -0.004156 & 0.001387 & -0.000032 & -0.000001 & 0.0021 & 0.3751 \\
\hline
\end{tabular}

Note: This table shows the results of cross-sectional regressions of average stock returns over 52 weeks on beta, gamma and delta of the four-moment CAPM. Corresponding p-values are given in parenthesis. Adj R2 column shows adjusted R2 value and the last column shows the F-statistics value for the overall significance of the model. Significant coefficients at the $10 \%$ and $5 \%$ levels are indicated with $*$ and $* *$ respectively.

\section{Table A8: Results of the test of the conditional four-moment CAPM}

\begin{tabular}{cccc}
\hline \hline Coefficient & Estimate & t stat & P value \\
\hline$\alpha$ & 0.001702 & 1.339675 & 0.2003 \\
$\lambda_{\beta}$ & -0.001077 & -0.709569 & 0.4889 \\
$\lambda_{\gamma}$ & -0.000508 & -1.923353 & $0.0736^{* *}$ \\
$\lambda_{\delta}$ & 0.0000681 & 1.079821 & 0.2973 \\
\hline Market risk premium & -0.001517 & -0.953428 & 0.3555 \\
$\left(\lambda_{\beta}+\lambda_{\gamma}+\lambda_{\delta}\right)$ & & & \\
\hline
\end{tabular}

Note: This table shows the results of test of four-moment CAPM. Significant coefficients at $5 \%$ level are indicated with $* *$. 